\title{
Editorial
}

Respiration 2006;73:737-738

DOI: $10.1159 / 000095908$

\section{Oxidative Stress during Exercise: Further Proof that Being Lean Is Detrimental for Chronic Obstructive Pulmonary Disease Patients}

\author{
Marco Confalonieri ${ }^{a} \quad$ Alfredo Chetta ${ }^{b}$ \\ a Department of Pneumology, University Hospital of Cattinara, Trieste, and \\ ${ }^{\mathrm{b}}$ Department of Clinical Sciences, Section of Respiratory Diseases, University of Parma, Parma, Italy
}

Peripheral muscle dysfunction is a clinically pertinent systemic effect of chronic obstructive pulmonary disease (COPD), since it can greatly contribute to exercise intolerance and reduce the patients' quality of life. [1]. Despite the fact that in clinical practice peripheral muscle dysfunction has been observed for a long time, the causes of this dysfunction have yet to be fully elucidated. Peripheral muscle dysfunction has primarily been explained by the sedentary lifestyle commonly adopted by COPD patients. Several studies have supported this notion by showing that physical training can improve peripheral muscle function, exercise tolerance and quality of life [24]. However, the most recent research favors the role of an intrinsic muscle disorder.

In patients with COPD, there is an increased oxidative burden which may be responsible not only for pulmonary effects but also for systemic ones, such as peripheral muscle dysfunction, depletion of body weight and loss of fatfree mass. In patients with pulmonary emphysema accompanied by a loss in skeletal muscle mass, a decreased muscle antioxidant potential, as indicated by low intracellular reduced glutathione (GSH) levels, was found in skeletal muscles at rest [5]. Skeletal muscle is also continuously exposed to changes in the redox environment, as occurs during exercise. The production of reactive oxygen species by the mitochondrial respiratory chain can significantly increase in COPD patients following exercise. Lipid peroxidation products are increased in serum from COPD patients during exercise accompanied by an increase in the ratio of the oxidized form of glutathione

\section{KARGER}

Fax +4161306 1234

E-Mail karger@karger.ch

www.karger.com
(C) 2006 S. Karger AG, Basel

0025-7931/06/0736-0737\$23.50/0

Accessible online at:

www.karger.com/res
(GSSG) to GSH [6]. In patients with COPD submitted to a training protocol, GSSG/GSH ratios were found to increase, whereas no such increase was seen in healthy controls [7]. This finding indicates a different capacity for COPD patients when compared to healthy individuals to adapt the redox system to the cellular demand for oxygen transport and consumption during training.

In the present issue of Respiration, Rabinovich et al. [8] presented novel but not surprising information about the effect of exercise on COPD patients with low body mass index (fig. 1). In fact, since we already know that COPD patients can develop an imbalance between oxidant and antioxidant systems, the observed link between weight loss and the enhanced vulnerability to oxidative stress after training and during high intensity exercise is rather important. The results of this study emphasize the need to carefully look at the nutritional status of COPD patients in daily clinical practice, especially before implementing a rehabilitation program in COPD patients with low body mass index. By definition, losing $10 \%$ of one's body weight over 6 months is considered a significant health risk [9], but this is particularly pertinent for COPD patients experiencing a more severe systemic disease with muscle wasting. A respiratory rehabilitation program can decrease exercise-induced oxidative stress in COPD [10], but most likely only patients without low body mass index and muscle wasting can really benefit. However, data showing a causal relation between reductions in inflammation and/or oxidative stress and improvement in exercise tolerance, outcomes of rehabilitation, or quality of 


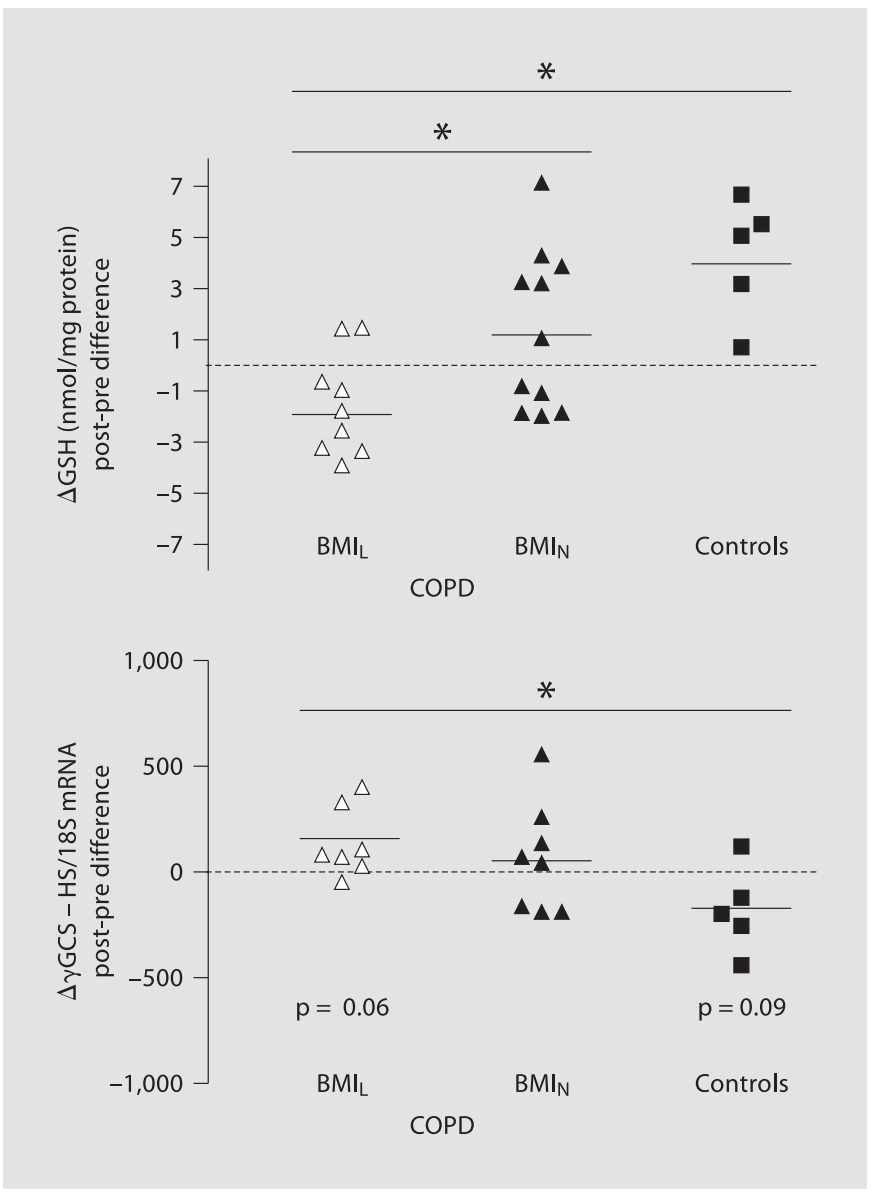

life are still lacking. A recent investigation published in the American Journal of Respiratory and Critical Care Medicine [11] suggests that normoxemic, muscle-wasted COPD patients could be protected from exposure to bursts of oxidative stress by supplemental oxygen during exercise, but this does not mean that muscle wasting and weight loss, which are reversible factors, can be avoided. In fact, a low body mass index has been shown to be better at predicting death and outcome in COPD patients than the traditional $\mathrm{FEV}_{1}$ [12]. As health systems in Western countries move forward in their fight against overweight and obesity in the general population they should consider that in the case of COPD patients, being lean and slim is counterproductive due to exercise-induced GSH depletion.

Fig. 1. Effect of exercise training on changes of glutathione $(\Delta \mathrm{GSH})$ and oxidized glutathione ( $\Delta \gamma \mathrm{GCS}-\mathrm{HS} / 18 \mathrm{~S} \mathrm{mRNA})$ in healthy sedentary subjects (controls) compared to COPD patients with low $\left(\mathrm{BMI}_{\mathrm{L}}\right)$ and normal $\left(\mathrm{BMI}_{\mathrm{N}}\right)$ body mass index. Upper panel: Individual (symbols) and mean (horizontal lines) changes in muscle reduced glutathione expressed as post- and pre-training differences. Post-training $\Delta \mathrm{GSH}$ showed an increase in controls, no changes in $\mathrm{BMI}_{\mathrm{N}}$, and a significant fall in $\mathrm{BMI}_{\mathrm{L}}\left({ }^{*} \mathrm{p}<0.005\right)$. Bottom panel: $\Delta \gamma \mathrm{GCS}-\mathrm{HS} / 18 \mathrm{~S}$ mRNA expression showed a trend to increase in $\mathrm{BMI}_{\mathrm{L}}$, no changes in $\mathrm{BMI}_{\mathrm{N}}$, and down-regulation in controls. Statistically significant differences were seen between $\mathrm{BMI}_{\mathrm{L}}$ and controls (* $\left.\mathrm{p}<0.05\right)$.

\section{References}

1 Wouters EFM: Chronic obstructive pulmonary disease. 5. Systemic effects of COPD. Thorax 2002;57:1067-1070.

2 Maltais F, LeBlanc P, Simard C, Jobin J, Berube C, Bruneau J, Carrier L, Belleau R: Skeletal muscle adaptation to endurance training in patients with chronic obstructive pulmonary disease. Am J Respir Crit Care Med 1996;154:442-447.

3 Serres I, Varray A, Vallet G, Micallef JP, Prefaut C: Improved skeletal muscle performance after individualized exercise training in patients with chronic obstructive pulmonary disease. J Cardiopulm Rehabil 1997;17: 232-238.

4 Lorenzi CM, Cilione C, Rizzardi R, Furino V, Bellantone T, Lugli D, Clini E: Occupational therapy and pulmonary rehabilitation of disabled COPD patients. Respiration 2004;71: 246-251.
5 Engelen MP, Schols AM, Does JD, Deutz NE, Wouters EF: Altered glutamate metabolism is associated with reduced muscle glutathione levels in patients with emphysema. Am J Respir Crit Care Med 2000;161:98-103.

6 Vina J, Servera E, Asensi M, Sastre J, Pallardo FV, Ferrero JA, Garcia-De-La-Asuncion J, Anton V, Marin J: Exercise causes blood glutathione oxidation in chronic obstructive pulmonary disease: prevention by $\mathrm{O}_{2}$ therapy. J Appl Physiol 1996;81:2198-2202.

7 Heunks LM, Dekhuijzen PN: Respiratory muscle function and free radicals: from cell to COPD. Thorax 2000;55:704-716.

8 Rabinovich RA, Ardite E, Mayer AM, Polo MF, Vilaró J, Argilés JM, Roca J: Training depletes muscle glutathione in patients with chronic obstructive pulmonary disease and low body mass index. Respiration 2006;73: 757-761.
9 Hill G, Pickford I: Malnutrition in surgical patients. Lancet 1977;689:192.

10 Merken EM, Hageman GJ, Schols AMW, Akkermans MA, Bast A, Wouters EFM: Rehabilitation decreases exercise-induced oxidative stress in chronic obstructive pulmonary disease. Am J Respir Crit Care Med 2005; 172:994-1002.

11 Van Helvoort HAC, Heijdra YF, Heunks LMA, Meijer PLM, Ruitenbeek W, Thijs HMH, Dekhuijzen PNR: Supplemental oxygen prevents exercise-induced oxidative stress in muscle-wasted patients with chronic obstructive pulmonary disease. Am J Respir Crit Care Med 2006;173:1122-1129.

12 Celli BR, Cote CG, Marin JM, Casanova C, Montes de Oca M, Mendes RA, Pinto Plata V, Cabral HJ: The body-mass index, airflow obstruction, dyspnea, and exercise capacity index in chronic obstructive pulmonary disease. N Engl J Med 2004;350:1005-1012. 